\title{
Afrocentric Science Education Approach in a Transformed Curriculum in Post-Apartheid South Africa
}

\author{
Ntokozo Mthembu \\ University of South Africa, Tshwane, SOUTH AFRICA \\ Faculty of Human Sciences, School of Social Sciences
}

Received 25 April 2019 • Revised 10 September 2019 • Accepted 1 October 2019

\begin{abstract}
The post-apartheid era in South Africa was intended to be a period in which to redress past injustices in almost all social spheres, including education, particularly in terms of curriculum transformation to include African-centered knowledge systems. However, research reveals the limitations posed by compensatory education, particularly when it comes to the provision of skills that instil self-reliance abilities. In attempting to gain a better understanding of such experiences, the qualitative research design was used to collect data by conducting face-to-face interviews with young people residing in the labor reserves in South Africa. Findings indicate that although some individuals possess certain academic qualifications, such qualifications tend to be limited in securing their livelihoods. Based on these findings, it is recommended that the curriculum incorporate the African knowledge systems to offer alternatives to assess the untapped skills that could be useful to individuals to secure their daily life needs.
\end{abstract}

Keywords: Afrocentric, science, transformation, curriculum, education, post-apartheid.

\section{Introduction}

Recently, the concept of transformation has become synonymous with that of decolonization, which has been central to discourses on social equity in learning and social landscapes in South Africa. A transformation goal in this context includes a curriculum that focuses on African content and considers variables such as equity, efficiency and access to values and elements that strengthen the teaching and learning processes. Such values and elements include Ubuntu, African languages, social justice and responsibility, as well as agency (Songca, 2017: 4). Africanization is a decolonization process that recognizes problems relating to colonial forms of knowledge, pedagogical strategies and research methodologies. In other words, transformation deals with individual, collective, cultural and institutional change that is aimed at inculcating high levels of proficiency and scholarship. The worldwide call for inclusive education has coincided with socio-political change in South Africa, which has been the driving force shaping the landscape and spirit of educational change (Phaahla, 2014: 31). For instance, in 2012, the African National Congress (ANC) government centralized the administration of provincial departments of education, which created equity in terms of education policy directives and led to systematic educational change (Ibid.: 31). In considering the drivers of change, the relevant stakeholders need to make policy decisions that will promote actual transformation. This article

(C) Authors. Terms and conditions of Creative Commons Attribution 4.0 International (CC BY 4.0) apply. Correspondence: Ntokozo Mthembu, P.O. Box 392, UNISA, o003, SOUTH AFRICA. E-mail: mthemnc@unisa.ac.za. 
seeks to emphasize the significance of an Afrocentric science-education approach to curriculum transformation through the use of indigenous African languages as drivers of change (Ibid.: 32).

Furthermore, Phaahla argues that it is imperative to consider the conceptual framework of a transformed curriculum, which was first implemented in America and Europe in the 1970s, where states tended to influence the determination of certain critical values and related policies (Ibid.: 32). Despite such progressive interventions, however, transformation in education in South Africa has remained biased towards the previously (and still) advantaged white populace. In South Africa, the discourse dealing with the advancement of indigenous African knowledge values consists of two opposing fronts: the first argues for the inclusion and acknowledgement of an African value system as part of a social cohesion strategy, while the second concedes that South Africa faces complex challenges, with already limited resources constrained by the availability of funding. This article is based on the premise that the use of indigenous African knowledge value systems as mediums of instruction in academia will promote equity, justice and the recognition of previously undermined values in South African society in general.

Specifically, this article aims to contribute by redressing the deficit in literature dealing with the vulnerability of unemployed black African youth, especially in relation to their lack of relevant skills and their survival strategies in post-apartheid South Africa. The author starts by exploring the literature in relation to a compensatory education system and the transformation of education. The significance of self-reliance is highlighted and the virtues and value of indigenous African knowledge systems acknowledged, while arguing that these should form the core of educational transformation in Africa as a whole. Next, the author outlines the methodology adopted, describes the research findings and gives a discussion, before concluding the article with a summary of the study and recommendations.

\section{Literature review}

\subsection{The sociology of knowledge}

Literature on the theory of the politics of knowledge, as espoused by Walter R. Mignolo, states that identifying the need for decolonization and decolonial knowledge is the first step towards a reimagination and reconstruction of a just community and anti-imperial/anticolonialist approach (2009: 2). The geopolitics of knowledge cannot be realized without a consideration of the geopolitics of knowing. Despite the adoption by the South African government of various policies geared towards educational transformation that includes indigenous African knowledge systems in the learning sphere, in reality, the inclusion of black African values remains debatable. Some of the related debates are emblematic of the fact that the current compensatory education system remains defined by the inculcating dependency syndrome, as it encourages the selling of individual labor power in the labor market. The theoretical framework used in this article is important, as highlighted by Mthembu (2015: 145), who advocates a Khushite perspective, which is a holistic approach that is paramount in encouraging the promotion of African values, particularly when it comes to a re-centering of black African knowledge systems across all social spheres (Ibid.: 145). Mignolo points to the significance of the notion of hubris of the zero point a means of observation that distinguishes between disconnected/colonized and neutral/colonizer, knowledge of the surroundings and its challenges, an ordering of people and the act of enforcing what the colonizer considers to be good for them. In addition, perhaps through the posing of questions such as "by whom?”, "when?", "why?" and "where?”, knowledge is generated, which helps to shift attention from the enunciated to the act of enunciation. The current awakening of people is occurring in places that were previously considered as anthropos, people perceived by a locus of enunciations to be self-defined as humanitas, as having no thought, as underdeveloped and as non-people by the West (Mignolo, 2009: 2). This scenario suggests two sets of paths adopted by the "former anthropos who are no longer claiming recognition by or inclusion in the 
humanitas scheme of things" (Ibid.: 3). The first path is defined as de-centering Westernization, as it clings to the current Western capitalist economy that perpetuates ideals of liberalism (i.e. rules of engagement are defined by elites collectively). This path, however, remains contested, as the practice of knowledge integration continues to present a variety of challenges (Erin \& Yiheyis, 2011: 5). The second path is described as the decolonial approach, which asserts that places or regions and people have been deliberately subjected to colonial violence, been underdeveloped economically and mentally, and segregated as anthropos and humanitas in order to entrench the racial categories of national groups. In other words, it means breaking away from the colonial approach and promotion of self-determination among the previously colonized nations.

\subsection{Research question}

The main focus was to explore the question that steered this study: What are the possibilities of an Afrocentric science-education approach in a transformed curriculum in postapartheid South Africa?

\subsection{Significance of the study}

This study is fundamental in contributing to the literature on assessing the relevance of education in relation to the provision of skills development, particularly in redressing past injustices and promoting self-reliance. In addition, this study might assist in formulating relevant curriculum content as part of incorporating indigenous knowledge systems - particularly Africancentered scientific knowledge - especially when it comes to the infusion of assessment methods of teaching and learning in the curriculum.

\section{Methodology}

\subsection{Research design, context, participants and sampling}

The research design adopted in the study, which was exploratory in nature, was relevant specifically because it employed a qualitative methodological framework. The qualitative approach is recommended particularly when attempting to gain an understanding of the context of participants' experiences (Mthembu, 2016: 5). Since qualitative research is in-depth in nature, it permitted the selection of a small number of participants to gather in-depth information regarding their experiences relating to the issue under investigation (Monique, Inge \& Ajay, 2011: 7). When narratives and documents are used to collect data, qualitative inquiry has been proven to be relevant, especially in the context of an exploratory investigation into the lives of people who are perceived to be vulnerable and underdeveloped (Ibid.:9). In the study under discussion, the qualitative framework presented adequate data, as it enabled participants to narrate their experiences of their vulnerability within their own communities. In addition, documentary analysis was used to collect data.

The participants in this study consisted of male and female African youth from KwaMashu township in KwaZulu-Natal province. Data were collected from a sample of youth between the ages of 18 and 29 years by means of in-depth interviews and focus group interviews. The snowballing approach was applied to identify additional participants for the in-depth interviews, with the requirement that they be young people from the area under study. Nonprobability sampling was applied in selecting participants who were unemployed (Eisenhardt, 2002: 433). The participants were drawn from two in-depth interviews and two focus group interviews with non-governmental organizations (NGOs) operating in the area under study. 


\subsection{Data collection}

A number of research questions were posed during the investigation; participants' biographies were examined; the difficulties the youth encountered in relation to their parents were explored; the challenges the participants encountered in meeting their daily needs were examined and survival strategies the participants employed to secure their livelihoods were articulated, following a perusal of the literature referenced earlier in the article, which was useful in outlining relevant themes for the study. The Khushite perspective was used in formulating questions to extract information on individual ability, to ascertain which challenges and weaknesses act as constraints preventing the participants from meeting their daily livelihood needs. The researcher took notes during the interviews and transcribed them soon afterwards. Data were also collected using semi-structured in-depth interviews with two selected participants. Two focus group interviews, with six and seven participants respectively, were conducted with participants who met the relevant requirements: they were young people who were seen to be idle, sitting around in groups in KwaMashu township. The focus groups had mixed representation in terms of gender, as there were four male and three female participants. The discursive nature of the focus group enabled the researcher to obtain a variety of shared personal perspectives on a social phenomenon. Four topics or themes came under investigation: the education system, economic capital accumulation methods, survival strategies and current social experiences.

\subsection{Establishing credibility and trustworthiness of data collected}

After clearance had been obtained from the University of South Africa's Ethics Committee, an initial interview was arranged with the first participant. All participants were required to complete consent forms, which informed them what the study was about. The participants were selected for the relevant roles they played in their respective communities (such as being unemployed or participating in NGO activities) and their influence on their environment. The focus group interviews were conducted on the street where participants spent their time idle during the day.

\subsection{Data analysis}

A framework analysis was used to analyze the data, focusing on five key stages: "familiarization, identifying a thematic framework, indexing, charting, mapping and interpretation" (Srivastava \& Thomson, 2009: 75). Leedy and Ormrod (2005: 136) emphasize that the use of a thematic approach makes it possible to develop themes from both the research questions and the participants' narratives. Triangulation was applied to validate the data: only a few in-depth interviews were held, but other data collection tools, such as focus group interviews and direct observation, were applied to assist in cross-checking the validity of the information gathered (Creswell, 2014: 15).

\section{Findings}

For reasons of feasibility and the purposes of this article, the following themes were extracted from the data: participants' biographies, participants' views on the education system, participants' survival strategies and present social experiences. 


\subsection{Participants' biographies}

Although young people are normally expected to still be focusing on issues pertaining to schooling, the social realities show that they are not homogeneous in this regard, as only some are still dependent on family support or furthering their studies. Generally, a number of young people drop out of school early for various reasons, including a lack of motivation to further their education and a lack of parental guidance. This is especially evident among those young people who engage in delinquent behavior that results in, among other things, pregnancy while still attending school (Mthembu, 2017: 15). Since the current research is concerned with the survival strategies of the youth, the researcher was interested in determining the skills that assisted participants in securing their livelihoods.

Some of the youth were considered delinquent, as the social setting of the township does not enable parents to inculcate community values such as respect, personal accountability or aspects of their respective cultures. There are various reasons for this, such as single-parent households, abusive homes and, most of all, the lack of time, as some parents spend most of their time at work in order to provide for their family's basic needs.

This scenario was emphasized by one of the participants during an in-depth interview, when the researcher was attempting to gain a better understanding of the challenges the youth encounter in relation to their parents. This participant stated:

"The worst part is that even our parents they don't have the way to guide us or curb us in case we go wrong in life because now we live a 'free life."

Changes in society have resulted in cultural values being altered; some activities, such as having a child outside of marriage, used to be taboo for young persons, but have become the norm in townships. This was emphasized by one of the participants, when asked about difficulties encountered in meeting daily needs:

“... except, if you talk about impregnating each other and drug abuse ... Furthermore, there is no relevant recreation infrastructure in our area, as we are not even allowed to use [the] community hall for our activities. We don't have even a simple playground for youth as there is only one for the whole township, that is why we are playing in the streets."

These reflections confirm what the literature states: that the township, or kasi, youth category consists of school dropouts, heavy drinkers of alcohol and individuals who are always partying and/or bored, have multiple sexual partners and end up with babies whom they cannot support (Swartz, 2009: 70).

\subsection{Level of education and views on the education system}

It is assumed that all individuals have been empowered through socialization to overcome the challenges they encounter in the course of life, but, in reality, such an assumption is groundless, since, as a result of the various obstacles they experience, a number of individuals become discouraged from pursuing any further endeavors aimed at securing a livelihood for themselves.

Education is viewed as one of the routes that can be followed in acquiring life- and jobrelated skills. However, the lack of skills is a significant factor contributing to unemployment. This scenario is made worse by the fact that the present compensatory education system in South Africa remains based on the periphery-center system that denies previously disadvantaged communities their cultural value systems. That means they remain marginalized and their language and environment are not taken into account (Ibid.: 145). The data confirm that achieving a post- 
secondary educational qualification is no guarantee of work or a formal job. This was emphasized by one of the respondents, who stated:

"The poor education that we have does not enable the individual to be employed."

This limiting form of social development was further emphasized by another participant, who reported:

"Although my parents could afford to pay for my tuition fees to continue with schooling to finish my Standard 8, I opted not to pursue it any further and to sell fruits in the market or collect scrap metal in the community and sell it, because the current education system tends to be foreign to my traditional aspirations, as it teaches me sell labor power as a worker, which is something that is alien and not African and also demeaning."

This also supports the argument put forward by Connell that the current partial social set-up, which has similar connections to marginalization, with discouraging effects on southern African populations especially, merits research exploration (2014: 212).

In attempting to understand what skills the participants in this study possessed, the author noted that the data confirmed what has been raised in the literature, namely that some young people drop out of school as a result of their chosen lifestyles and the attitudes they hold (Swartz, 2009: 75). This was observed during the data collection phase, where a number of young people reported being engaged in various cottage industry activities, such as producing beadwork or grass brooms and working in small spaza shops (convenience stores located in private homes and stalls alongside a footpath or walkway, and in the context of the study, in the streets near KwaMashu station or the larger township).

Despite the post-apartheid government's attempts to reinforce labor market-oriented skills, the author's interviews with young people in KwaMashu showed that the capitalist-oriented education system still functions according to the same "pass or fail" code, which systematically excludes certain individuals from accessing an education and promotes the division of learners into different future labor categories.

This was stressed by one of the participants during the focus group interview:

"The FETs [Further Education and Training sector] must be open to everybody and standby procedures at registration must end. For example, when you go to register in June and you will be told that they will phone you and they end up not phoning you."

The interviews also revealed that parts of the education system apparatus still conform to bad management practices and resemble the pre-1994 education system, which did not take black African learners seriously in their quest to achieve a solid education.

The effects of a poor education system were identified by one of the participants, who expressed the following view during the interview:

"One of the challenges that some of us experience after you have enroll[led] to the FET colleges, [is that] there is a lack of relevant infrastructure to study effectively. For example, if you study under a tree, you only end up memorizing everything instead of having learning equipment that will help [the] learner to know exactly what is spoken about, not only end up theorizing what is supposed to be learnt and done... learners don't get their results and when they request results they are told to enroll for the second level without knowledge of their previous class results..."

The data confirm that although the government has promulgated legislation aimed at the development of young people, maladministration and corruption remain rife (Stats SA, 2015: 34). This further serves to prevent other learners from enrolling for their studies and indirectly 
contributes to undermining the optimism of young people, who see no way of furthering their careers (Connell, 1993: 22).

\subsection{Survival strategies}

Usually, community members view young people from a variety of perspectives. Some argue that the youth do not contribute to the community and are "otsotsi" (criminals), drug abusers, "a lost generation" and "a generation in crisis" (ILO, 2015: 4). Arguably, most of these labels tend to be applied by people who are financially self-sufficient, employed and lack a critical and expansive understanding of the social issues that the black African community in general are experiencing in contemporary South Africa.

When the researcher investigated the survival strategies adopted by the participants, the latter reported engaging in the following activities in their communities:

"I organize crime awareness and educational campaigns in the community."

"I'm spreading the word of peace in the community."

"I organize dance groups for young people and also perform for elderly people."

The data confirm that although skills are important, physical health is also imperative in the process of developing the wellbeing of others by building relationships that act as conduits of encouragement and helping to meet individuals' livelihood needs.

During the interviews, participants were selective in responding to the questions posed. When the researcher asked what role they played in their respective communities, not all participants responded.

Some stated that they were not doing anything, while others had the following to say:

"I belong and work with social movements that wish to bring development in the area."

"I volunteer in assisting and participate in different activities that my communities ask me to do, i.e. community safety activities that protect workers against criminals when they come back from work."

"I organize crime awareness and educational campaigns in the community and I assist to train young people when they play on the sport grounds."

These youth activities reflect the strength of the relationships they, as individuals, have established in the community; through their networks, they are able to engage in certain activities in order to make a living (Bilobrova \& Tul, 2015).

Furthermore, the initiatives reveal the potential of these young people and the various possibilities for integrating them into society to enable them to contribute as equal partners to developing their society. Two further participant responses appear below:

"I stay at home and receive a grant; [without] that grant I was going to live just like other people who cannot meet their daily needs."

"A person is a person through other people, it's good that you be friends with different people, so that you can get help in times when you need it."

Community relationships are important because, in that context, individuals are able to rely on social networks (such as friends or relatives) for support to make a living (NdlovuGatsheni, 2013: 87). Although several participants came up with alternatives to meet their subsistence needs, the data revealed various constraints that the participants had to contend with 
in their endeavors to make a living, as revealed by the response of one of the participants during an in-depth interview:

"Opening a stall after I attended a workshop in 20o8, then I decided to start something, as my income of R9oo per month was not sufficient to meet all my needs. I started selling items like cigarettes in the workplace where I was working as a machine operator, a skill that I learn[ed] whilst I was working there. The idea of opening a stall came after I was selling low-cost chips, sweets, and broken cake crumbs in 2006 for some time, then when the company closed down I started increasing the items that I sell by adding three telephone booths which I bought with the last money I received as my retrenchment package."

Participants who revealed their means of survival tended to focus on ways of making money and securing food, but they also highlighted other strategies (i.e. help from family members, parents or friends; depending on their own resourcefulness or self-reliance; and social agencies, such as government department/s) that guaranteed the security of their daily livelihoods. In addition, the data show that all activities that participants identified as important for their survival were not only meant to guarantee a source of income, but were also aimed at personal satisfaction (Ibid.: 87). However, such initiatives frequently collapsed owing to a lack of the necessary support (e.g. finance) to improve their business and management skills (DeJaeghere \& Baxter, 2014: 77).

\subsection{Present social experiences}

When the researcher explored the experiences of the youth (township dwellers, in particular) and their relevance in post-apartheid South Africa, the question of the problems they encountered in meeting their daily needs, such as food and shelter, arose.

Participants had the following to say in this regard:

"Increase [in] food prices... that make[s] it hard to afford to live daily."

"The rise of family members' disputes at home, because of being unemployed and need[ing] food."

"It is sorrow and poverty that [are] very humiliating at present."

A similar situation was observed during the data collection process. For instance, the researcher noted that some young people could not afford to buy food when they were hungry, and so resorted to scavenging for food in dustbins, or begging for money to buy food. The researcher also observed that some of these young people were referred to as beggars, which opened them to treatment such as either being chased away or being offered leftovers or a few coins. Some of the unemployed youth did not have shelter or a home where they could sleep at night, and their appearance and clothing indicated that they had little access to facilities for washing. The demeaning social setting in which they found themselves added the extra burden of stress, frustration and humiliation to their lives.

The data confirm what is argued by Casale and Thurlow (1999), namely that township life can be regarded as a "living hell", as young people still live and are quarantined in the "underdeveloped" township areas.

Participants emphasized the lack of financial support, the limitations of the labor market, the outcomes of their situation, a shortage of relevant information from development stakeholders (government, youth development agencies) and limitations in respect of accessing social services:

"It's a lack of money to meet my daily needs such as food and decent clothes." 
"The lack of employment opportunities and that is frustrating at present."

"Crime, jobless, stress and homeless are the major problem at present."

"Lack of relevant information such as skills training that can help me to get a job that is hard to get at present."

"Cigarettes smoking is the problem and that affects my thinking when I did not smoke, especially as I cannot afford to buy it."

\subsection{Unique findings}

Given this situation, a great deal of human potential remains untapped. A number of young people are becoming disillusioned, as emphasized in another in-depth interview (Bilobrova \& Tul, 2015).

On being asked about the challenges the youth encounter in their day-to-day experiences, a participant reported as follows:

"Other problems that are rife among the young people are that we as young people, we do not want to study and when you speak about education it's like you are talking about a beast ... Another thing is that the current education standard in the township is meant for creating tools to be used by other people, as there [are] no educational structures that are meant to offer training to young people about selfreliance."

Substantial numbers of young people lack an education or a skill that could help them to improve their lives or meet their daily needs under the present socio-political conditions. In the section that follows, the author examines the survival strategies that the youth adopt in dealing with the everyday difficulties they encounter.

\section{Discussion}

The data emanating from this study reveal that young people remain vulnerable to poverty, a lack of relevant skills, unemployment and food price increases, just as do other members of the public who cannot afford food, despite having access to employment and other related benefits such as social grants from government. The data suggest a need to consider the vulnerability perspective, especially when evaluating disadvantaged communities or individuals (Angelsen \& Dokken, 2015: 8). Opinions relating to this subject differ, as it could be argued that the agencies in question are not doing enough to inform young people about what is available to them in order for them to further develop themselves (NYDA, 2015: 43).

This view is supported by the fact that some young people lack information on how to advance their skills and/or access FETs. This suggests that access to institutions for further education remains exclusive, as was the case during apartheid, where the standard attained (e.g. Matric) determined a candidate's eligibility to enroll. Although government has introduced programs that partly deal with this situation, the difficulties cited above place government in a bad light, suggesting that it does not care or does not do enough to curb this neglect.

The impact of colonization on education resulted in the alteration of social values from lifelong education values and natural abilities to labor market-aligned values (Do Vale, 2016: 595). Therefore, when an individual faces unemployment, he/she cannot devise an alternative livelihood, despite his/her educational achievements. This inability tends to exacerbate the rate of unemployment and the cycle of poverty in society, especially among previously disadvantaged communities. However, unemployment affects the less educated and graduates almost in the same way, even when it comes to the use of their natural abilities. The opportunity for employment is 
higher for graduates than for the less educated, but they all have to sustain their lives without being employed or selling their labor power. Education systems that fail to encompass and acknowledge other cultural systems of knowledge are at risk of being viewed as oppressive and being opposed by individuals who feel disadvantaged. However, the slow response to a series of calls for change of the curriculum regarding the theory and practice of the present "post-colonial" era remains of grave concern. Cajetas-Saranza (2015: 39) cites four historically constructed reasons that can be linked to this incongruity in curriculum change:

- Sustenance of capitalist ideas through satisfying the demands of the proletarized individuals, people who are denied their way of living (self-reliance), but letting learners depend on selling their labor power for their livelihood;

- Upholding the neoliberal capitalist values;

○ Discouraging/ preventing educators from inculcating local culture and using cultural studies as a form of pedagogy

$\circ$ Dehumanizing the self-discovery of the indigenous people's own social and cultural value systems

In South Africa, the role of education in serving the labor-market demands is widely acknowledged (there has been a lack of speculation about dealing with the high rate of unemployment). The nature of unemployment in South Africa is considered to be structural and encapsulates the mismatch between the skills endowment of individuals and surplus labor, which is an extra labor force that is always available for the efficient functioning of the capitalist economic system (Mlatsheni, 2012: 32). This situation suggests that although individuals can achieve high skills and have related high chances of employability, there is no guarantee of absorption into the labor market. The nature of the education system is another factor that should be considered.

\section{Conclusion and recommendations}

Theoretically, the type of education relative to skills can also influence an individual's ability to be self-reliant and employed. Education should be fairly accessible to equip individuals with skills that focus not only on labor-market demands, but also on their abilities to be selfreliant. When deliberating on curriculum change, the transformative learning perspective states that the process of "perspective transformation consists of three aspects: psychological that focuses on the understanding of the self, conviction that deals with belief systems, and behavior centered on the changes in lifestyle" (Heilman \& Clarke, 2016: 42). The transformative learning perspective identifies four basic features that shape a transformative approach to learning, which form part of the educational processes (Ibid.: 42). These features consist of individual experience, critical reflection, dialogue and action. Thus, the development of a realistic approach is significant for guaranteeing the sound relationship between learner, educator and their milieu.

The critical fact is that the new curriculum should achieve accessibility to and satisfaction for learners, impart technical and generic skills and guarantee equity of different cultural backgrounds. In summary, a new curriculum must be holistic in nature in order to be able to address pre-1994 constraints in the South Africa education system (Singh, 2015: 57).

The achievement of a desired outcome, such as livelihood improvement skills for learners, depends not only on the expansion of capabilities available as options to them, but also on the functioning they choose. Therefore, the point of transformation between capabilities and functioning draws attention to the possibility that the learners may use their capabilities in a manner that could contribute both positively and negatively to their personal livelihoods, families and communities. There are two points of transformation, which are from endowments to capabilities, and from capabilities to functioning (DeJaeghere \& Baxter, 2014: 71). This approach 
suggests that the first transformation from endowments to capabilities is influenced by structures of constraint. The second transformation, from capabilities to functioning, entails an active choice between the opportunities accessible. Given that individual and societal contexts define values, these varieties are also mediated by the structures of constraint that affect how individuals can use their endowments. This aspect of the approach suggests that it is not only the valued options or capabilities available to learners that count for their livelihoods, but also the actual choice to pursue a particular option for the purposes of securing a livelihood (Ibid.: 71). In summary, the data show the significance of, and the need for, different approaches to support young people in order to enable them to contribute effectively and become knowledgeable citizens.

Overcoming the challenges cited and introducing indigenous African knowledge systems in the educational sphere, in fulfilment of the aspirations set out in the Constitution of this country, is a mammoth task. This remains the case, despite the promulgation of a pioneering centralized education policy that led to the establishment of a single education department and raised the hopes of previously disadvantaged communities. It shows that there are still obstacles to overcome in respect of the general transformation of education (including higher education and research, especially when it comes to advancing indigenous African value systems). The relevance of education and of human capabilities is fundamental to transformative multicultural education that is tailor-made for a post-colonial society. Coupled with this understanding is the aspiration towards knowledge creation that is free from bias. That aspiration can be attained when knowledge increases awareness of and seeks to dismantle the covert and overt features of power dynamics within our education system and the broader community through the diffusion and rendering of emancipatory and Afrocentric knowledge to all people, regardless of social status.

Although the study was based on a small sample, it is argued that the participants did not differ significantly from those in other, similar communities. The findings confirm two topographies, as suggested by Walter R. Mignolo's analysis, namely that the present education system espouses individual development that promotes the anthropos setting and, second, the humanitas scheme. This article emphasises the Khushite ideal, which argues that African indigenous value systems are paramount when defining education for sustainable development, which requires a holistic approach (Mthembu, 2015: 145). The participants in this study offered insights into their experiences of the links between skills, education and poverty. In particular, they emphasized the significance of an education that is relevant to their socioeconomic and cultural value system, against the broader social context in which a skills shortage limits innovation and, consequently, intellectual disability and dependency syndrome. This is highlighted by Connell, who notes that the current layering of the social set-up is linked to marginalization, with discouraging effects (1993: 22). The findings of the study reported on here suggest that examples of marginalization are readily observable among young people in township communities. In addition, the findings are aligned with Mignolo's (2009) decolonial approach, which suggests breaking away from the Eurocentric social setting that asserts that certain places, regions and people have been deliberately subjected to violence, underdeveloped economically and mentally, and segregated. Phaahla (2014) attests that the objective of educational transformation should include a curriculum that encompasses African values and gives consideration to variables such as equity, efficiency and access to those values that strengthen the teaching and learning process, such as Ubuntu, language, social justice and responsibility, and agency. Some young people who opt to drop out of school lack the skills to secure their livelihoods and self-reliance abilities. An alternative and emancipatory education system often becomes the only viable means of enabling previously disadvantaged people to work towards individual selfdiscovery and self-reliance (Songca, 2017: 4). Therefore, it is recommended that further research explore a future curriculum that engages with the development of learners' personal and selfreliance abilities. 


\section{Acknowledgements}

This research did not receive any specific grant from funding agencies in the public commercial, or not-for-profit sectors.

The author declares no competing interests.

\section{References}

Angelsen, A., \& Dokken, T. (2015). Environmental reliance, climate exposure, and vulnerability: A cross section analysis of structural and stochastic poverty. World Bank Policy Research Working Paper, 7474. Retrieved 20 January 2019, from http://documents.worldbank.org/curated/en/756811468197347850/Environmentalreliance-climate-exposure-and-vulnerability-a-cross-section-analysis-of-structural-andstochastic-poverty.

Bilobrova, T. O., \& Tul, S. I. (2015). Jobless society - phenomenon of global economy: Economic processes management. International Scientific E-Journal 3. Retrieved 20 January 2019, from http://epm.fem.sumdu.edu.ua/download/2015 3/2015 3 10.pdf.

Bohensky, E. L., \& Maru, Y. (2011). Indigenous knowledge, science and resilience: What have we learned from a decade of international literature on "integration"? Ecology and Society, 16(4), 6.

Cajetas-Saranza, R. (2015). Approaches to integrating multicultural perspectives in PNU-Mindanao: Basis for multicultural education program. International Peer Reviewed Journal, 16, 37-55.

Casale, D., \& Thurlow, J. (1999). Poverty, inequality and human development in the Durban Metropolitan Area (Durban: Economic Development Department, Durban Metropolitan Council. Retrieved 20 January 2019, from http://repository.uwc.ac.za/xmlui/handle/10566/18.

Connell, R. W. (1993). Schools and social justice. Philadelphia: Temple.

Connell, R. (2014). Using Southern theory: Decolonizing social thought in theory, research and application. Planning Theory, 13(2), 210-223.

Creswell, J. W. (2014). Qualitative, quantitative and mix method approaches. 4th edition. Thousand Oaks: Sage.

DeJaeghere, J., \& Baxter, A. (2014). Entrepreneurship education for youth in sub-Saharan Africa: A capabilities approach as an alternative framework to neoliberalism's individualizing risks. Progress in Development Studies, 14(1), 61-76.

Do Vale, H. F. (2016). Explaining education reforms and decentralization in Brazil, South Africa, South Korea, and Spain. Journal of Local Self-Government, 4(3), 591-612.

Eisenhardt, K. M. (2002). Building theories from case studies. In: M. C. Hubermann \& M. B. Miles (Eds.), The qualitative researcher's companion. Thousand Oaks: Sage.

Heilman, D. C., \& Clarke, D. L. (2016). Transformative learning theory: Perspectives on Nelson Mandela and application for U.S. learners in South Africa. In: S.M. Tomlinson-Clarke \& D. L. Clarke (Eds.), Social justice and transformative learning: Culture and identity in the United States and South Africa (pp. 40-57). New York: Routledge.

Hennink, M., Hutter, I., \& Bailey, A. (2011). Qualitative research methods. Thousand Oaks: Sage.

International Labour Organization (2015). Global employment trends for youth 2015: Scaling up investments in decent jobs for youth. Geneva: ILO.

Leedy, P. D., \& Ormrod, J. E. (2005). Practical research. Upper Saddle River: Pearson Prentice-Hall. 
Mignolo, W. R. (2009). Epistemic disobedience, independent thought and de-colonial freedom. Theory, Culture \& Society, 26(7/8), 1-23.

Mlatsheni, C. (2012). The challenges unemployment imposes on youth. In: H. Perold, N. Cloete \& J. Papier (Eds.), Shaping the future of South Africa's youth: Rethinking post-school education and skills training (pp. 31-41). Cape Town: Centre for Higher Education Transformation (CHET).

Mthembu, N. (2015). Finding our head without losing our feet: Morality of circumcision among the Zulus. Wandsbeck: Reach.

Mthembu, N. (2016). Youth challenges in the transition to adulthood in a South African township. Youth Voice Journal, 6, 1-18.

Mthembu, N. C. (2017). Black African township youth survival strategies in post-apartheid South Africa: A case study of the KwaMashu township within eThekwini Municipality. PhD thesis. Tshwane: University of South Africa.

National Youth Development Agency (South Africa) (2015). National Youth Development Agency Annual Report, 2014-2015. Pretoria.

Ndlovu-Gatsheni, S. J. (2013). Coloniality of power in postcolonial Africa: Myths of decolonization. Dakar: CODESRIA.

Phaahla, P. (2014). Indigenous African languages as agents of change in the transformation of higher education institutions in South Africa. Nordic Journal of African Studies, 23(1), 31-56.

Singh, R. J. (2015). Use of blended learning in higher education - some experiences. Progressio, 37(1), 5467.

Songca, R. (2017). College of Law (CLAW) humanized legal education and transformative curriculum guidelines. Working Paper. Retrieved 17 January 2019, from http://hdl.handle.net/10500/22452.

Srivastava, A., \& Thomson, S. B. (2009). Framework analysis: A qualitative methodology for an applied policy research note. Journal of Administration and Governance, 4(2), 1-8.

Statistics South Africa (StatsSA) (2015). Quarterly labour force survey - Q1, 2015. Pretoria.

Swartz, S. (2009). The moral ecology of South Africa's township youth. New York: Palgrave MacMillan. 
N. Mthembu - Afrocentric Science Education Approach in a Transformed Curriculum...

C O A $\mathrm{s}$ 